\title{
Retroperitoneal perforation of the rectum during double-contrast barium-enema examination: a life-threatening complication
}

\author{
Mehmet Yildirim $^{1}$, Ozgur Oztekin ${ }^{2}$, M. Emrah Bayam ${ }^{1}$, Erdal Yagli ${ }^{1}$, Savas Yakan $^{1}$ \\ ${ }^{1}$ Department of Surgery, ${ }^{2}$ Department of Radiology, \\ Izmir Bozyaka Teaching and Research Hospital, Izmir, Turkey
}

Background. Rectal injuries during barium-enema are rare but life-threatening complications.

Case report. We present a case of an 82-year-old man in whom extensive retroperitoneal perforation of the rectum occurred during double-contrast barium-enema examination. The patient was revealed acute abdomen, difficulty in breathing and diffuse subcutaneous crepitus at the chest and neck area. The patient underwent a surgery because signs of peritonitis developed. We performed a Hartmann's procedure. The patient died 20 hours after the surgery due to a septic shock.

Conclusions. Prompt recognition and management of retroperitoneal perforation of the rectum are sine qua non in decreasing mortality.

Key words: rectal perforation; barium-enema

\section{Introduction}

Rectal perforation is a rare complication of the barium-enema examination. The clinical presentation varies according to the anatomic location and degree of the rectal injury. Extensive retroperitoneal emphysema and barium may cause acute abdomen and respiratory distress. The diagnosis is based on the clinical and imaging studies. ${ }^{1}$ The radiographic findings depend upon the volume of extravased air and barium.

Received 11 January 2009

Accepted 25 February 2009

Correspondence to: dr. Mehmet Yildirim, Atakent Mah.Bergama 2 Apt.Giris:32 Daire:1, Bostanlý/Izmir, Turkey. Phone: 0090 2323625692; Fax: 0090232 2614444; E-mail: mehmetyildi@gmail.com
Perforative rectal injuries have been categorized by Ault. ${ }^{2}$ Injuries of Category 1 and 2 are mild injuries that meaning patients can be treated with conservative methods. Category 3 and up are accompanied by septic infection and high mortality rate. In this article, we report about a case of retroperitoneal rectum perforation due to barium-enema examination.

\section{Case report}

An 82-year-old man was admitted to Izmir Bozyaka Teaching and Research Hospital, Department of Surgery with a history of diffuse abdominal pain, swallowing and dyspnoea of 3 hours duration. 


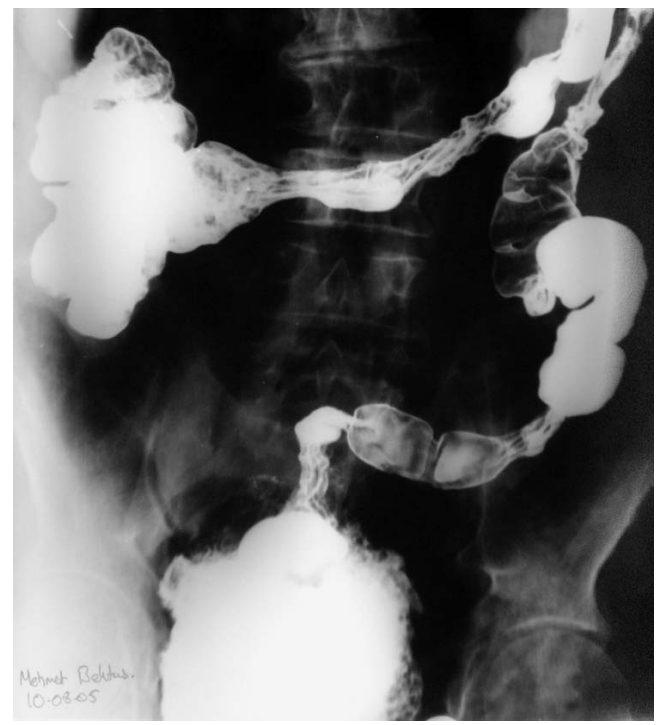

Figure 1. Presence of perirectal extravasation of barium in double-contrast barium-enema examination.

He was presented with a history of twomonth's constipation and weakness. For differential diagnosis, barium-enema with additional air-contrast study was performed 4 hours before in Radiology Department. Later on, on the same day, the patient developed abdominal complaints associated with breathing difficulties. When admitted, his temperature was $38^{\circ} \mathrm{C}$, blood pressure was 110/70 $\mathrm{mm} \mathrm{Hg}$, pulse rate $90 \mathrm{bpm}$ and breath rate $24 \mathrm{bpm}$. The double-contrast barium-enema examination showed the perirectal extravasation of barium (Figure 1).

On examination he had generalised abdominal tenderness with guarding, rebound tenderness, swallowing and diffuse subcutaneous crepitus in the chest and neck area. Rectal examination showed that blood passed per-rectum. Laboratory studies showed a WBC count of $14 \times 10^{9} \mathrm{~L}$ and $20 \times 10^{9} \mathrm{~L}$. A roentgenogram of the chest showed free air in the peritoneal cavity, in the retroperitoneal space in the mediastinum and subcutaneous emphysema (Figure 2). Computerized tomography showed perirectal barium and subcutaneous emphy-

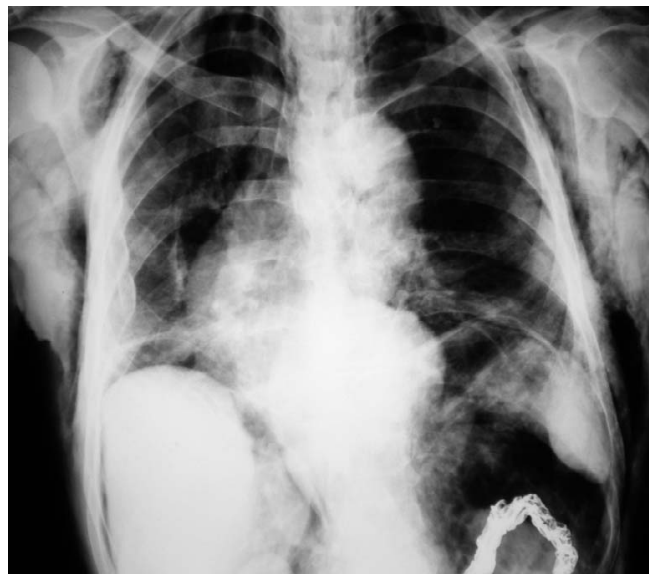

Figure 2. Erect chest $X$-ray at presentation demonstrates air under the diaphragm, in mediastinum and subcutaneous emphysema.

sema (Figure 3). Based upon these clinical and radiological findings we suspected that a perforation of the rectum occurred.

After the initial resuscitation in our clinic, the patient underwent a midline transperitoneal laparotomy during which was found out that he suffered to an extraperitoneal perforation in the posterior wall of the rectum. The perirectal tissues were of emphysematous nature and soiled with barium. In the retroperitoneum and anterior abdominal wall a large amount of barium and oedema, involving the muscle, fascia and subcutanous tissues was found extraperitoneally. The mesenterium of sigmoid colon was widened with the large amount of barium. The perforation wasn't suitable for suture repair and the Hartmann's procedure was done. Large irrigation tubes were inserted into the rectovesical fossa. At the intensive care unit postoperatively, he was in a shock with temperature of $36.5^{\circ} \mathrm{C}$, blood pressure of $70 / 40 \mathrm{mmHg}$, a pulse of $130 \mathrm{bpm}$, and a respiratory rate of $30 \mathrm{bpm}$. Later he developed to multiple organ dysfunction syndrome and systemic inflammatory response syndrome and he died 20 hours after operation. 


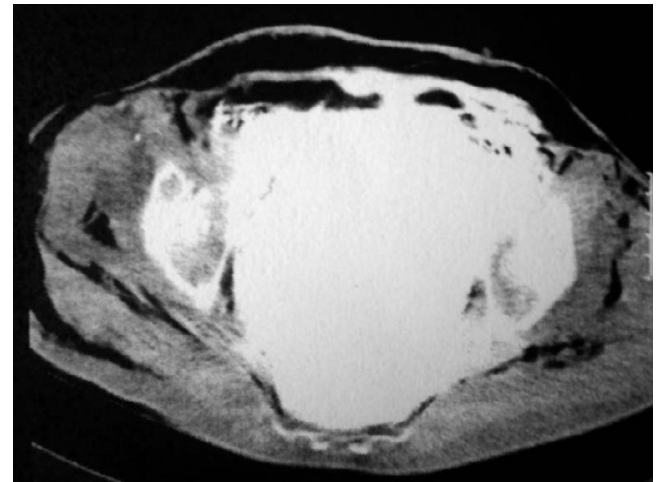

Figure 3. CT showed perirectal migration of barium in pelvic cavity and subcutaneous emphysema.

\section{Discussion}

Rectal perforation following double-contrast barium-enema examination is uncommon. Terranova et al. ${ }^{3}$ reported that this complication occurred in 1\% of all barium studies. In the study of Fry et al. ${ }^{4}$ rectum or sigmoid colon perforations were found in 5 cases among the 2200 barium-enema examinations performed during a 4-year period.

The most frequent causes of rectal perforations are traumatic injury of the tip of the enema catheter or presumably the excessive hydrostatic pressure. In some studies, intraluminal lesions such as cancer, diverticulum or rectal biopsies were reported pre-existing factors. ${ }^{1}$ Rectal perforations may be either intraperitoneal or extraperitoneal. Five types of perforations have been described based upon anatomic boundaries. Category 1 includes perforations of the anal canal below the levator ani muscle. Category 2 is incomplete perforations with only perforation of rectal mucosa. These perforations involve lower or/and middle third of rectum extraperitoneally. They present rectal pain and bleeding. Surgery is not always required for Category 1 and 2 perforations. These perforations can be treated conservatively with broad- spectrum antibiotics.
Surgery is required only in cases of large perforations and when the extravasation of large amount of barium occurs. Category 3 includes rectal perforation above the levator muscle but below the peritoneal reflection. Retroperitoneal injury may cause difficulty in breathing, cyanosis, abdominal discomfort, and shoulder pain. Category 4 covers transmural perforation into the adjacent organs and Category 5 the intraperitoneal perforation. Half of surgically confirmed rectal injuries in Category 2 are painless or they occur with delayed pain.

In our case Category 3 perforation with extensive retroperitoneal and subcutaneous emphysema was determined. Subcutaneous emphysema in the chest, neck and scrotal areas were identified by physical examination. Clinically signs of difficulty in breathing, swallowing in the cervical area and subcutaneous crepitus were found in our patient. After few hours leucocytosis $(20 \mathrm{x}$ $\left.10^{9} \mathrm{~L}\right)$, tachycardia and fever developed.

The radiological findings in each case depend upon the amount and nature of extravaseted material. In most radiological reports extravasation of air was found more frequent than barium leakage. ${ }^{2}$ The perirectal air may dissect tissue plans extending into the retroperitoneal area gathering under the diaphragm. In our case extension of large volume air into the mediastinum and soft tissue of the neck resulted difficulty in breathing.

The retroperitoneal emphysema generally resolves within 1-2 weeks without sequelae. ${ }^{5}$ In contrast as in our case spillage of dense barium and air produced progressive, fatal septic shock.

The treatment of retroperitoneal perforations depends on the clinical status and severity of perforations. Intraperitoneal or large retroperitoneal perforations must be treated by prompt laparotomy with removal of barium and drainage of abdominal cavity. During laparotomy a careful search for 
injury of adjacent organs must be conducted. Primary repair of rectal perforations should be performed in appropriate cases. An end colostomy (Hartmann's procedure, colostomy of Devine, end colostomy with mucus fistula) must be performed to provide a defunctioning stoma. ${ }^{6}$

The studies suggests that the incidence of rectal perforation during barium-enema can be reduced by performing anoscopy prior to barium enema, avoiding the use of rectal balloon in rectal lesions, using a lower pressure and concentration of barium. ${ }^{3}$

\section{Conclusions}

Retroperitoneal perforations of rectum need immediate aggressive critical care because of the high mortality. Radiologist and surgeons must be able to communicate closely to achieve a better result.

\section{References}

1. de Feiter PW, Soeters PB, Dejong CH. Rectal perforations after barium enema: a review. Dis Colon Rectum 2006; 49: 261-71.

2. Peterson N, Rohrmann CA,Lennard ES. Diagnosis and treatment of retroperitoneal perforation complicating the double-contrast barium-enema examination. Radiology 1982; 144: 249-52.

3. Terranova O, Meneghello A, Battocchio F, Martella B, Celi D, Nistri R. Perforation of the extraperitoneal rectum during barium enema. Int Surg 1989; 74: 13-6.

4. Fry RD, Shemesh EI, Kodner IJ, Fleshman JW, Timmcke AE. Perforation of the rectum and sigmoid colon during barium-enema examination. Dis Colon Rectum 1989; 32: 759-64.

5. Tadros S, Watters JM. Retroperitoneal perforation of the rectum during barium enema examination. Can J Surg 1998; 31: 49-50.

6. Eu KW, Seow-Choen F, Goh HS. Unusual rectal perforation - an individualised approach to management. Singapore Med J 1994; 35: 79-81. 